\title{
On Power Augmentation of VAWT in the wake of a bluff body
}

\author{
Ammar Naseem, Zaib Ali, Emad Uddin \\ Department of Mechanical Engineering, School of Mechanical and Manufacturing Engineering (SMME) \\ National University of Sciences and Technology (NUST) \\ Islamabad, Pakistan 46000
}

\begin{abstract}
A numerical investigation of the performance of an H-Darrieus vertical axis wind turbine (VAWT) in the presence of a bluff body is performed. In particular, the impact of vortices shed by bluff bodies on the turbine performance is investigated. The deflected wind from the buildings possess wind velocity that can be up to $12 \%$ higher than the free stream wind velocity in case of a single building structure. The power enhancement of the VAWTs deployed downstream of a bluff body is analyzed by changing the location of the turbine in the wake of the bluff body and an optimal turbine mounting position is found.
\end{abstract}

Keywords: Vertical axis wind turbines, Bluff body, Wake interaction, Power augmentation.

\section{Introduction}

Vertical axis wind turbines can harvest energy from wind in any direction. This makes them suitable for urban deployment. VAWTs do not require any yaw or pitch mechanism for the rotor and the blades, respectively. Horizontal axis wind turbines face fatigue due to turbulent and gusty winds, however VAWTs have the ability to take advantage of such wind conditions. Strong support structures are not required for VAWTs as the gearbox, generator and other heavy components are mounted on the ground. This makes the replacement of turbine components simple and significantly reduces the maintenance costs. A study suggests that arrangement of VAWTs in an array that follows the natural phenomenon of fish schooling, the land area required for wind farm is reduced significantly. This results in increased power per unit area, generated by VAWTs as compared to HAWTs in wind farms $[1,2]$. The efficiency of VAWTs is low as compared to HAWTs as a single blade of the turbine produces maximum torque at a given instance of time in a complete rotation. Other major disadvantage of VAWT is the dynamic stall of the blades, as the angle of attack is changing rapidly throughout the rotational cycle of the turbine $[3,4]$. Turbine efficiency is reduced, noise and structural vibrations are induced due to the phenomenon of dynamic stall.

A modern urban area comprises of both high rise and low-rise buildings. The VAWT mounted on the top a low-rise building can take advantage of the wake flow behind a high-rise building which acts as a bluff body. Bluff bodies are studied for performance enhancement of VAWTs, it is found that if a flat plate deflector is placed in the path of the wind perpendicular to the direction of flow it becomes a vortex shedder as other bluff bodies. If a deflector is placed between the wind path and the wind turbine, at a specific location, the turbine rotational speed increases which in turn increases the power output of the turbine. This deflector bluff body acts as an augmentation device which enhances the power coefficient by $33 \%$ [5].

In this work, performance of VAWT is investigated in the downstream region of bluff bodies such as a high-rise building in an urban area. These bluff bodies shed vortices, the effects of these wakes on the turbine performance is investigated. The distance (axial and lateral) of the turbine from an urban structure is varied to find out the optimal point where power can be maximized.

\section{VAWT Test Case}

The wind turbine used for this study has a design based upon the Multiple Stream Tube Model (MSTM) as described in [6]. The wind turbine is 3 straight bladed H-rotor capable of producing $10 \mathrm{~kW}$ at $12 \mathrm{~m} / \mathrm{s}$ wind speed. The specifications and design parameters of the test case are given in the Table 1. 
Table 1: Design Parameters.

\begin{tabular}{|c|c|c|c|c|c|c|c|c|c|c|c|c|}
\hline Parameter & $\begin{array}{c}\text { Power } \\
(\mathrm{kW})\end{array}$ & Airfoil & $\begin{array}{c}\text { Wind } \\
\text { speed } \\
(\mathrm{m} / \mathrm{s})\end{array}$ & $\begin{array}{c}\text { Air } \\
\text { density } \\
\left(\mathrm{Kg} / \mathrm{m}^{3}\right)\end{array}$ & $\begin{array}{c}\text { Kinematic } \\
\text { air } \\
\text { viscosity } \\
\left(\mathrm{m}^{2} / \mathrm{s}\right)\end{array}$ & $\begin{array}{c}\text { Rotor } \\
\text { aspect } \\
\text { ratio } \\
(\mathrm{h} / \mathrm{R})\end{array}$ & $\begin{array}{c}\text { Number } \\
\text { of } \\
\text { blades } \\
\left(\mathrm{N}_{\mathrm{b}}\right)\end{array}$ & $\begin{array}{c}\text { Reynolds } \\
\text { number } \\
(\mathrm{Re})\end{array}$ & $\begin{array}{c}\mathrm{c}_{\text {pmax }}, \\
\sigma_{\text {cpmax }}, \\
\lambda_{\text {cpmax }}\end{array}$ & $\begin{array}{c}\text { Rotor } \\
\text { radius } \\
(\mathrm{m})\end{array}$ & $\begin{array}{c}\text { Airfoil } \\
\text { chord } \\
\text { length } \\
(\mathrm{m})\end{array}$ & $\begin{array}{c}\text { Rotational } \\
\text { speed } \\
(\mathrm{rad} / \mathrm{s})\end{array}$ \\
\hline Value & 10 & NACA0018 & 12 & 1.177 & $\begin{array}{c}1.568 \times 10^{-} \\
5\end{array}$ & 0.6 & 3 & $9.57 \times 10^{5}$ & $\begin{array}{c}0.475, \\
0.3,\end{array}$ & 4 & 0.4 \\
\hline
\end{tabular}

\section{Computational Setup}

Based on the geometric data given in the Table 1, a computational domain consisting of two parts, rotating fluid domain and static domain, is generated as shown in Figure 1(a).

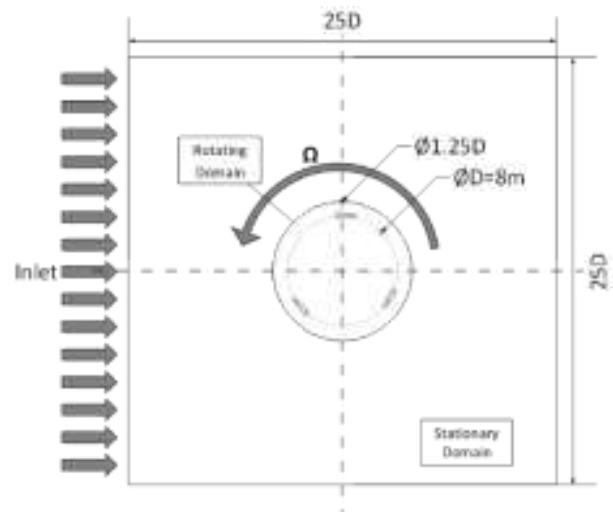

(a)

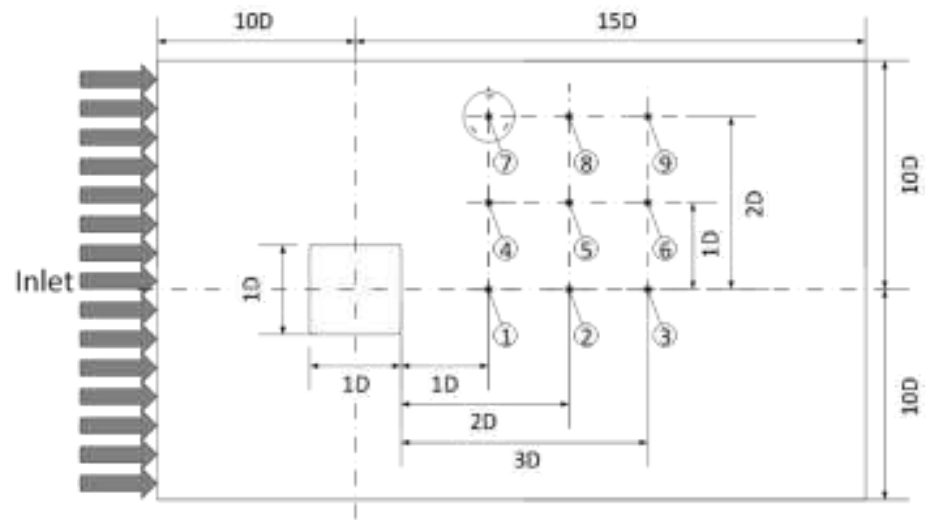

(b)

Fig. 1: Computational Domains (a) around the VAWT, (b) full domain with the single bluff body.

Figure 1 (b) shows the full computation domain including the single building and different locations of the turbine along with various lengths in terms of $\mathrm{D}=20 \mathrm{~m}$, the length of one side of the bluff body. The wind flow in the downstream region of bluff bodies has been considered while selecting the locations of the wind turbine. A total of nine different cases have been formulated. In these cases, the wind turbine location has been changed in the $\mathrm{x}$ and y directions. Table 2 shows the distances of wind turbine from the urban structure for both scenarios.

Table 2: Wind Turbine Locations for Single Urban Structure.

\begin{tabular}{|c|c|c|c|c|c|c|c|c|}
\hline \multicolumn{9}{|c|}{ Location } \\
\hline 1 & 2 & 3 & 4 & 5 & 6 & 7 & 8 & 9 \\
\hline $\mathrm{X}=1 \mathrm{D}$ & $\mathrm{X}=2 \mathrm{D}$ & $\mathrm{X}=3 \mathrm{D}$ & $\mathrm{X}=1 \mathrm{D}$ & $\mathrm{X}=2 \mathrm{D}$ & $\mathrm{X}=3 \mathrm{D}$ & $\mathrm{X}=1 \mathrm{D}$ & $\mathrm{X}=2 \mathrm{D}$ & $\mathrm{X}=3 \mathrm{D}$ \\
$\mathrm{Y}=0 \mathrm{D}$ & $\mathrm{Y}=0 \mathrm{D}$ & $\mathrm{Y}=0 \mathrm{D}$ & $\mathrm{Y}=1 \mathrm{D}$ & $\mathrm{Y}=1 \mathrm{D}$ & $\mathrm{Y}=1 \mathrm{D}$ & $\mathrm{Y}=2 \mathrm{D}$ & $\mathrm{Y}=2 \mathrm{D}$ & $\mathrm{Y}=2 \mathrm{D}$ \\
\hline
\end{tabular}

These locations have been set after detailed analysis the wind flow deflected by bluff bodies. The main strategy behind selecting these locations is to analyze the effects of deflected wind flow characteristics on the performance of the wind turbine appropriately. To make this study and comparison simple the wind turbine locations are related to urban structure dimension $\mathrm{D}$ starting from $0 \mathrm{D}$ and $1 \mathrm{D}$ in $\mathrm{x}$ and $\mathrm{y}$ directions respectively, with the increment of 1 . The flow characteristics have no significant variation, if the distances between two consecutive wind turbine locations are reduced. If the distances are increased, the wind turbine performance cannot be analyzed appropriately as it will skip some of the key locations at which the wind flow characteristics have been altered due to deflection. These flow characteristics are discussed in detail in the next sections.

The upstream wind velocity has been varied from $3 \mathrm{~m} / \mathrm{s}$ to $12 \mathrm{~m} / \mathrm{s}$ with an increment of $1 \mathrm{~m} / \mathrm{s}$ and the flow is considered incompressible. A $300 \mathrm{~K}$ ambient temperature has been considered for this study. Upstream flow is considered laminar. After 
interaction with the urban structure and wind turbine blades the flow is considered turbulent. To model the rotation of the wind turbine, a moving reference frame has to be incorporated in the domain.

Grid independence study has been carried out on six grids of different resolutions. Number of cells, corresponding to each grid resolution, has been compared with the coefficient of lift generated on each blade of the wind turbine. Initially a coarse grid of 70k cells has been generated, the cell count has been approximately doubled for each new grid resolution until an optimum grid resolution has been obtained. The grid independence study is shown in Figure 2.

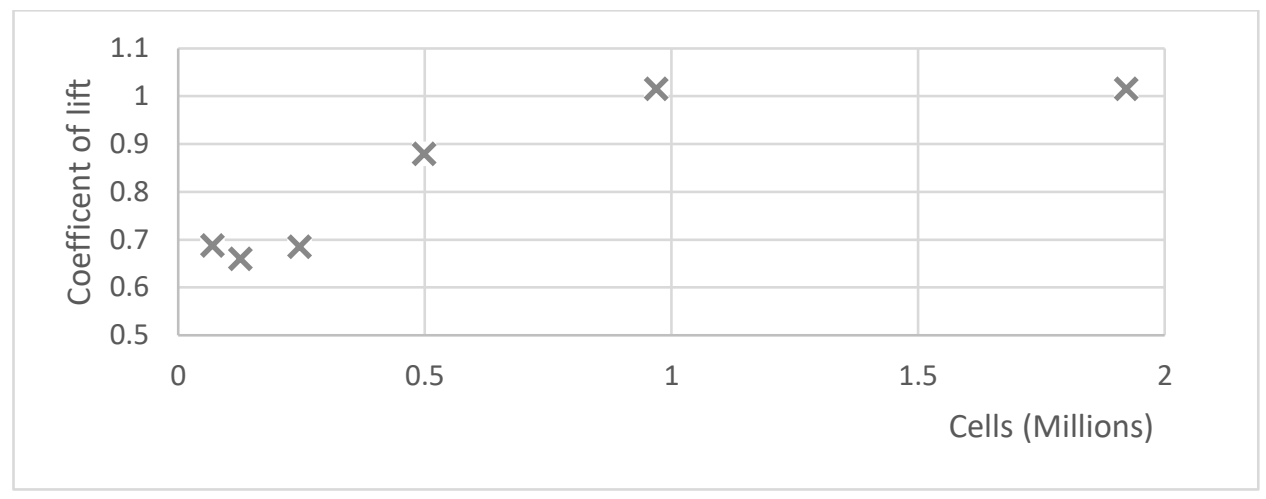

Fig. 2: Grid Independence.

The grid independence study suggested that coefficient of lift has no significant change when the grid resolution is between 1 Million (M) and $2 \mathrm{M}$ cells. The domains have been meshed according to the results of the grid independence test. The optimum grid cell count is $1.2 \mathrm{M}$ cells. A $\mathrm{y}^{+}$value of 5 is used.

\section{Results and Discussion}

\subsection{Validation}

The case was validated by comparing the power output obtained from experimental data, analytical calculations, Reynolds Averaged Navier Stokes (RANS) based numerical solver using the SST $k-w$ turbulence model [7] and Qblade software [8]. The experimental data has been obtained from the product specification sheet of Aeolos V-10KW wind turbine [9]. Although, Aeolos V-10KW wind turbine has different aspect ratio than the wind turbine designed for this study, the turbines show the same trend in their performance at different wind speeds. Therefore, data retrieved from all the above mention sources leads to a good validation study.

The domain used for the validation study is shown in Figure 1(a). The turbine power was calculated analytically at different wind speeds ranging from $3 \mathrm{~m} / \mathrm{s}$ to $12 \mathrm{~m} / \mathrm{s}$ using Equations. (1) - (3) below as described in previous work [6]. Coefficient of moment $C_{m}$ for each blade has been obtained from the numerical solver for 10 revolutions of the turbine. $C_{m}$ for last 2 revolutions was averaged and power was calculated by Eq. $(2,3)$.

$$
\begin{gathered}
P=\frac{1}{2} \rho V_{o}{ }^{3} 2 R H C_{p} \\
\tau=\frac{1}{2} \rho C_{m} V_{o}^{2} H S \\
P=\tau \omega
\end{gathered}
$$

The power for all blades calculated from Eq. (3) have been summed up to obtain the wind turbine power. Power comparison is shown in Figure 3. Validation study shows that the power output from the numerical solver follows the same trend as of experimental and Qblade data for different wind velocities. It reflects that power of the wind turbine at low wind velocities obtained from different data sources has a nominal difference. However, at high wind velocities the difference increases but the overall trend remains the same. 


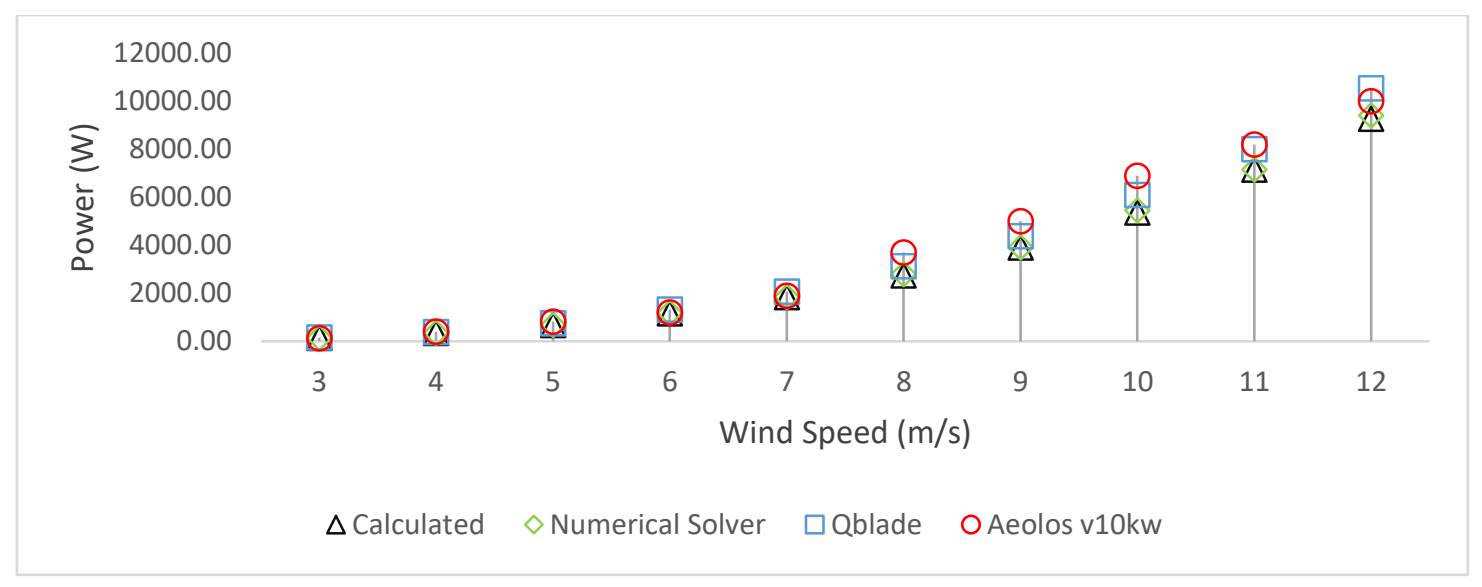

Fig. 3: Power Comparison (validation).

\subsection{Wake interaction}

The performance of the wind turbine has been investigated for a single bluff body in front. This scenario was tested to visualize the vortex shedding of the building and its effect on the flow velocity. Vortex shed from the bluff body require 20.16 seconds to complete one cycle. This complete vortex cycle is shown in the Figure 4. Here, the augmentation in the free stream velocity after deflection by an urban structure is shown. Before analyzing the wind turbine performance in this scenario, various velocity magnitude probes have been placed in the downstream region of the urban structure. These probes helped to analyze the flow characteristics of the wind in the downstream region. The output of these probes have been recorded and averaged over the complete cycle of 20.16 seconds. It has been established that, wind speed is augmented after deflection from the bluff body. This fact has also been confirmed in a previous study [5]. Keeping the results of this analysis, nine locations have been picked for the analysis of wind turbines power output.

In the case of single urban structure as wind deflection device, Figure 4 shows the flow characteristics. After 5.4 seconds a deflected wave is forming near the building walls shown in Figure 4(a). This wave will augment the wind speed in the downstream region. Figure 4 (b, c, d \& e) show that the defected wave is passing through the wind turbine locations. At these instances it is found that the wind speed at locations 2,4,5,7 and 8 has been augmented initially, but later wind speed diminishes at locations 2 and 4. This means that the urban structure has favorable and adverse effects on the downstream wind speeds. This trend of wind speed augmentation and diminution at deferent locations has been shown in Fig. 5.

Location of wind turbine was changed as shown in the schematic Figure 2(b). The coefficient of moments calculated at different locations were compared with the results in free stream.

Table 3: Comparison of turbine $C_{m}$ calculated at different locations and in free stream (single building).

\begin{tabular}{lcccccccccc}
\hline \hline & Bare Turbine & \multicolumn{10}{c}{ Location } \\
\cline { 2 - 10 } & & 1 & 2 & 3 & 4 & 5 & 6 & 7 & 8 & 9 \\
& & $\mathrm{X}=1 \mathrm{D}$ & $\mathrm{X}=2 \mathrm{D}$ & $\mathrm{X}=3 \mathrm{D}$ & $\mathrm{X}=1 \mathrm{D}$ & $\mathrm{X}=2 \mathrm{D}$ & $\mathrm{X}=3 \mathrm{D}$ & $\mathrm{X}=1 \mathrm{D}$ & $\mathrm{X}=2 \mathrm{D}$ & $\mathrm{X}=3 \mathrm{D}$ \\
& & $\mathrm{Y}=0 \mathrm{D}$ & $\mathrm{Y}=0 \mathrm{D}$ & $\mathrm{Y}=0 \mathrm{D}$ & $\mathrm{Y}=1 \mathrm{D}$ & $\mathrm{Y}=1 \mathrm{D}$ & $\mathrm{Y}=1 \mathrm{D}$ & $\mathrm{Y}=2 \mathrm{D}$ & $\mathrm{Y}=2 \mathrm{D}$ & $\mathrm{Y}=2 \mathrm{D}$ \\
\hline Averaged $\mathrm{C}_{\mathrm{m}}$ & 1.78 & 1.57 & 1.41 & 1.36 & 1.67 & 1.96 & 2.05 & 2.21 & 2.00 & 1.96 \\
Change $(\%)$ & - & -12 & -21 & -24 & -06 & 10 & 15 & 24 & 12 & 10 \\
\hline
\end{tabular}

Results mentioned in Table 3 shows that coefficient of moment is affected by the vortex shedding of buildings. The coefficient of moment is enhanced up to $24 \%$. In case of the single building used as deflector the suitable turbine locations are $\mathrm{X}=(2 \mathrm{D}$ and $3 \mathrm{D})$ at $\mathrm{Y}=1 \mathrm{D}$ and $\mathrm{X}=(1 \mathrm{D}, 2 \mathrm{D}$ and $3 \mathrm{D})$ at $\mathrm{Y}=2 \mathrm{D}$. 


\section{Conclusion}

In this study the performance of an H-rotor vertical axis wind turbine is investigated in an urban environment. The study is conducted by varying the location of the wind turbine in the wake of a tall urban structure. The characteristics of wind flow were analyzed and simulated. The study shows a potential in power augmentation when used at specific location in the wake region of the building. The buildings act as deflectors and subsequently augment the wind turbine power. The deflected wind from the buildings, near the wake region, possesses high wind velocity. As the power possessed by wind is directly proportional to the cube of upstream velocity, the higher velocity wind behind the bluff body enhances the rotor RPM and turbine power output.

According to the simulation results, the power of the VAWT is dependent on its location in the downstream of building. At optimum locations, the high wind velocity enhances the torque generated on the turbine blades which subsequently increases the power output of the VAWT. If the turbine is located in other locations the wind speed reduces which decreases the power output of the VAWT significantly. The average $C_{m}$ was increased by $24 \%$. From this study it is found that the roof mounted VAWTs can be deployed in the wake region of taller buildings for power augmentation. The effect of more parameters of the buildings such as aspect ratio and their different shapes could be explored in the future. Moreover, high fidelity simulation like Large Eddy Simulations (LES) could be performed to have a more accurate analysis. 


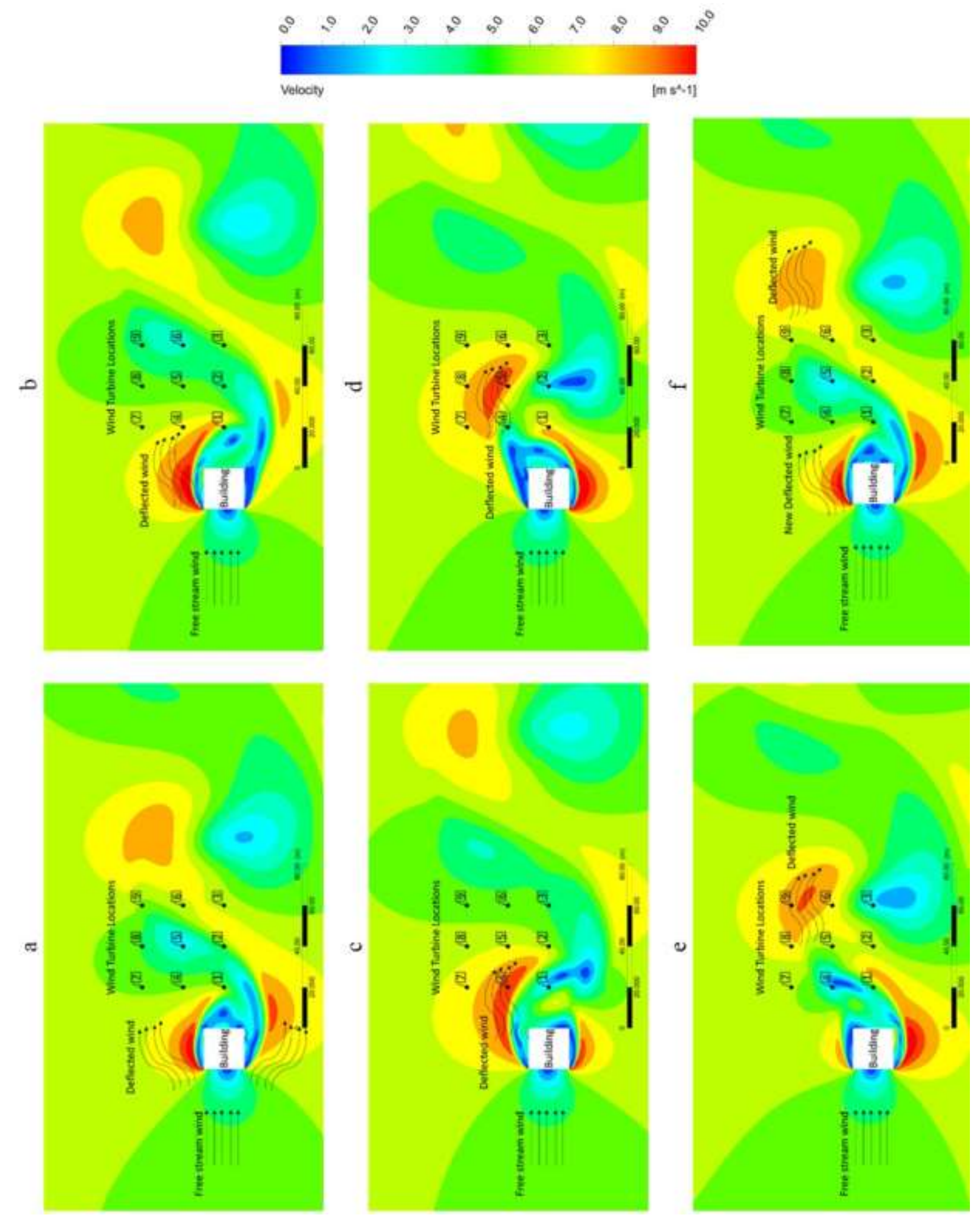

Fig. 4: Velocity contours for flow behind a single structure. 


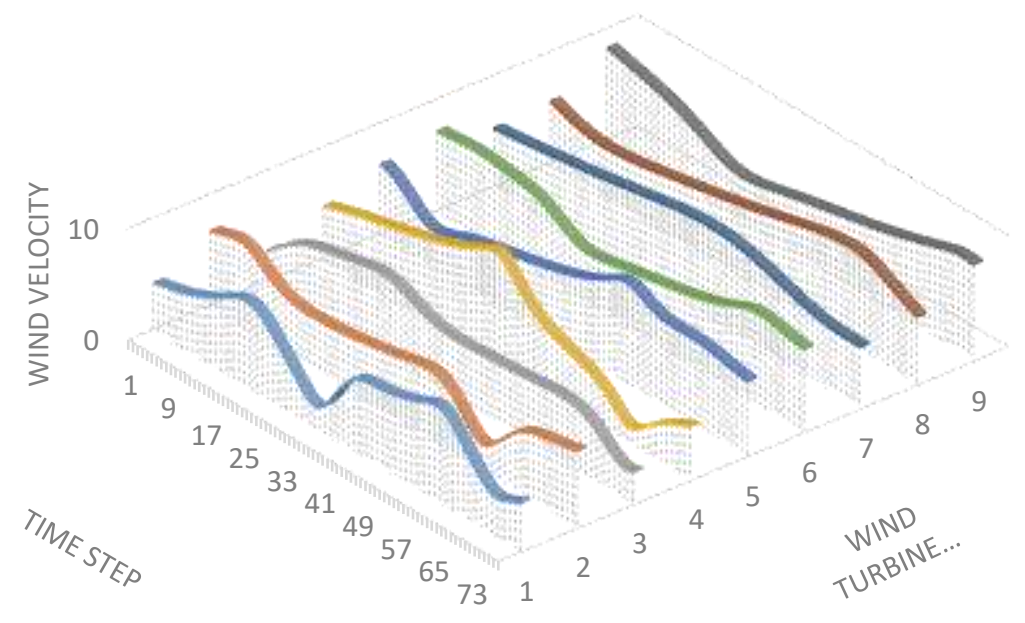

Fig. 5: Wind velocities at different wind turbine locations.

\section{References}

[1] R. W. Whittlesey, S. Liska, and J. O. Dabiri, "Fish schooling as a basis for vertical axis wind turbine farm design," Bioinspiration \& biomimetics, vol. 5, pp. 035005, 2010.

[2] J. O. Dabiri, "Potential order-of-magnitude enhancement of wind farm power density via counter-rotating verticalaxis wind turbine arrays," Journal of renewable and sustainable energy, vol. 3, pp. 043104, 2011.

[3] A.-J. Buchner, J. Soria, D. Honnery, and A. J. Smits, "Dynamic stall in vertical axis wind turbines: scaling and topological considerations," Journal of Fluid Mechanics, vol. 841, pp. 746-766, 2018.

[4] A. Buchner, M. Lohry, L. Martinelli, J. Soria, and A. Smits, "Dynamic stall in vertical axis wind turbines: comparing experiments and computations," Journal of Wind Engineering and Industrial Aerodynamics, vol. 146, pp. 163-171, 2015.

[5] K. H. Wong, W. T. Chong, N. L. Sukiman, Y.-C. Shiah, S. C. Poh, K. Sopian,W.-C. Wang, "Experimental and simulation investigation into the effects of a flat plate deflector on vertical axis wind turbine," Energy Conversion and Management, vol. 160, pp. 109-125, 2018.

[6] S. Brusca, R. Lanzafame, and M. Messina, "Design of a vertical-axis wind turbine: how the aspect ratio affects the turbine's performance," International Journal of Energy and Environmental Engineering, vol. 5, pp. 333-340, 2014.

[7] ANSYS Fluent. [Online]. Available: https://www.ansys.com/products/fluids/ansys-fluent

[8] D. Marten, J. Wendler, G. Pechlivanoglou, C. Nayeri, and C. Paschereit, "QBLADE: an open source tool for design and simulation of horizontal and vertical axis wind turbines," Int. J. Emerging Technol. Adv. Eng, vol. 3, pp. 264-269, 2013.

[9] "Aeolos-V Vertical Wind Turbine Brochure," Personal Correspondance. 